\title{
An analysis of the quality of paediatric prescription writing among medical officers in a teaching hospital
}

\author{
G K C Guruge $^{1}$, T Sorubarajan ${ }^{2}$, M V F Jayasuriya ${ }^{3}$ \\ Sri Lanka Journal of Child Health, 2008; 37: 12-16
}

(Key words: paediatric prescription writing, medical officers)

\begin{abstract}
Objectives To assess the quality of paediatric prescription writing and determine the factors associated with it.

Design Cross sectional descriptive study.

Method Firstly, 500 paediatric prescriptions from the outpatient department (OPD) were analyzed. Secondly, 297 doctors (excluding Consultants) from the Teaching Hospital, Kalubowila, were given case scenarios and asked to write appropriate prescriptions which were analyzed.
\end{abstract}

Results OPD prescriptions seemed satisfactory even though the designation and identification of the prescriber were notable omissions. In the case scenarios $20 \%$ wrote low quality prescriptions. Postgraduate Institute of Medicine (PGIM) trainees wrote better prescriptions than house officers who in turn wrote better prescriptions than medical officers. Those who did paediatrics for internship produced better prescriptions than others. Out of the paediatric related examinations, diploma in child health $(\mathrm{DCH})$ seemed to have a positive effect on prescription writing. Paracetamol dosage was written correctly by only $46.7 \%$ with $8.1 \%$ writing potentially toxic doses.

Conclusions Much can be achieved in prescription writing. Regular in-service training and doing paediatrics for the internship appear to be remedial measures.

\section{Introduction}

The quality of prescription writing is not up to standard and is a cause for concern globally ${ }^{1,2}$. Poorly

${ }^{1}$ Consultant Paediatrician, ${ }^{2}$ Senior Registrar in Paediatrics, ${ }^{3}$ Lecturer in Community Medicine, University of Sri Jayawardanapura

(Received on 10 March 2007. Accepted 10 April 2007) written prescriptions reduce the quality of standard care. It can lead to either toxic doses or inadequate doses with the possibility of antibiotic resistance. Litigation is another problem where doctors are concerned.

We planned to study the Sri Lankan situation in paediatric prescription writing in two parts. The first part was an analysis of the outpatient department (OPD) prescription pattern at present. In the second part, case scenarios were given to the participants and the quality of the prescriptions was analyzed. It gives us some idea of the theoretical knowledge the doctors have about prescription writing and their capabilities in writing ideal prescriptions, even though they may not do so in actual practice.

\section{Objectives}

- To assess the quality of paediatric prescriptions written by OPD officers.

- To compare the quality of paediatric prescription writing in 3 categories of medical staff viz. house officers (HOs), medical officers and senior house officers (grouped as MOs), registrars and senior registrars (PGIM trainees).

- To determine the relationship between the quality of paediatric prescription writing and the following factors:

○ Doing paediatric internship.

○ Post intern paediatric exposure.

- Doctors holding paediatric related diplomas i.e. diploma in child health (DCH) or diploma in family medicine (DFM).

\section{Setting}

The study was conducted at the Colombo South Teaching Hospital, Kalubowila from 1.10.2006 to 
31.10.2006. The ethics committee of Colombo South Teaching Hospital granted ethical clearance.

\section{Method}

In the first part of the study, OPD paediatric prescriptions issued from 1st of October 2006 were selected. All prescriptions where the age was below 12 years were taken in until 500 were collected. As the name, sex, age and date are written on the prescription by non-medical staff in the OPD before patients meet OPD doctors, the analysis was restricted to the dose, frequency of the drugs, the duration of the treatment and designation and identification of the prescriber.

In the second part, 3 paediatric case scenarios were given to 15 doctors (as a pilot study) and they were asked to write appropriate prescriptions for each particular case scenario. After going through those prescriptions carefully, deficiencies in the case scenarios were corrected accordingly. Later, case scenarios were given to all doctors working in teaching hospital, Kalubowila except those who participated in the pilot study, consultants and those who involved in administrative work. We gave case scenarios individually after taking verbal consent and giving an assurance that the participants were free to stay unidentified in the prescription. They were given enough time and their doubts were clarified. In the first case scenario each participant was expected to write each component of a complete prescription (full name of patient, age, address, date, drug, signature and designation) for a patient with viral fever. After receiving the first completed prescriptions from the participants, the second and third case scenarios were given. Second case scenario tested the ability of a doctor to choose an appropriate antibiotic for a baby with symptomatic culture positive urinary tract infection. Third case scenario dealt with a patient with congenital hypothyroidism and the correct way of writing thyroxine dose. For the doctors who wanted to see the deficiencies and mistakes in their prescriptions, which most did eagerly, their deficiencies were pointed out.

In the analysis of case scenarios each component was given marks according to a preplanned marking scheme. Each component of prescription writing carried a mark of 10 and incomplete answers received less marks.

\section{Results}

In the first part of the study (OPD prescriptions) the doses of the drug were written by $99.2 \%$, frequency by $97.2 \%$ and duration by $95.6 \%$ of the OPD doctors but the designation as well as the identification of the prescriber was not seen on any of the prescriptions. In the second part (case scenario) there were 297 doctors, out of whom 68 were house officers. Total number of medical officers and senior house officers was 165 with 41 of them working in the OPD. In the senior registrar and registrar category there were 64 of whom 14 were paediatric senior registrars or registrars.

When the total score is considered the results are as follows:

Total number of participants 297 Maximum score that can be achieved 185 Mean score 113.65

Median of the scores

Standard Deviation (SD) $\quad 28.56$

Range of the scores

Figure 1 shows the distribution of the score.

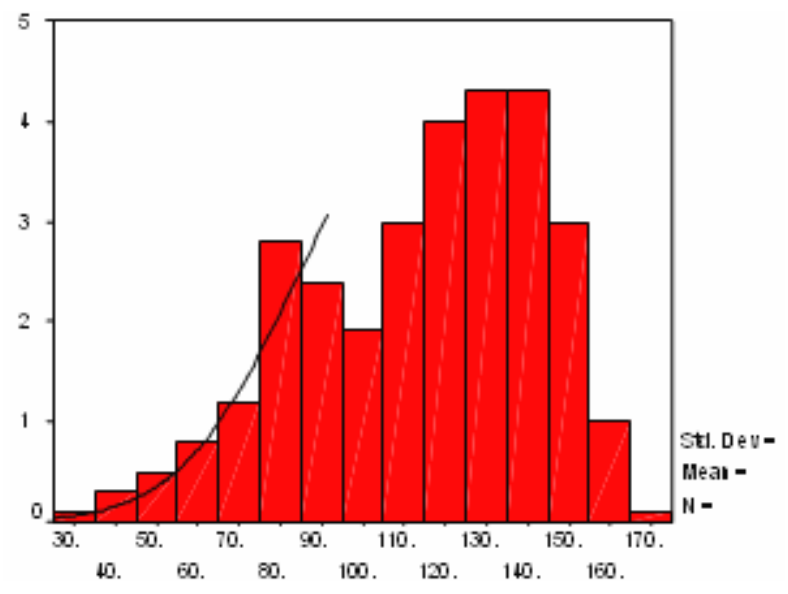

Figure 1 Distribution of score

The total score was categorized as poor, satisfactory and good. As the distribution curve was slightly negatively skewed, median was taken as the reference point. Those scoring one standard deviation (SD) below the median were grouped as poor, those between median $\pm 1 \mathrm{SD}$ as satisfactory and those who scored 1SD above the median as good. According to these criteria $19.9 \%$ scored poorly, $63.3 \%$ got satisfactory marks and $16.8 \%$ achieved good results.

Total scores of the different categories were then compared. The mean score for senior registrar /registrar (PGIM trainee) category was 124.36 \pm 28.9 . The HO category came second with a mean of $117.87 \pm 29.71$. The group with the lowest score was the MO category with a mean of $107.69 \pm 26.49$. The 
difference observed in above 3 categories is significant $(\mathrm{P}<0.001)$.

Next, the effect of doing paediatrics for internship on paediatric prescription writing was studied. 104 (35\%) doctors, who did paediatrics for internship, wrote good prescriptions compared to those who did not $(\mathrm{P}=0.04)$. The quality of prescription writing was not significantly different in participants who worked in a paediatric ward after internship compared to those who did not $(\mathrm{P}=0.25)$.

The quality of prescription writing was better in 18 $(06 \%)$ doctors who had the DCH qualification than in those who did not $\{\mathrm{P}=0.02\}$. However, in 29 $(09.8 \%)$ doctors who had the DFM qualification, there was no statistically significant association between DFM and quality of paediatric prescription writing $(\mathrm{P}=0.77)$.

Although we examined 18 components of the prescription writing, paracetamol dose was separately assessed. In the first case scenario we mentioned the age and body weight of a patient and expected all doctors to write the correct and practicable dose. The results were disappointing. Only $46.7 \%$ candidates wrote the correct dose. $10.1 \%$ had written either inappropriately high or very low doses. $8.1 \%$ have written a dose more than $90 \mathrm{mg} / \mathrm{kg} / \mathrm{day}$, which can cause liver failure. Furthermore, paracetamol was written as PCM by $24.5 \%$ participants and as panadol by another $2.4 \%$. When the frequency is considered $65.6 \%$ wrote regular doses of paracetomol and $34.4 \%$ wrote as s.o.s/prn/ if needed. Only $5.4 \%$ gave clear directions as not more than 4 doses per day.

In the first case scenario the diagnosis was given as viral fever. However 5\% have written antibiotics in the prescription. For the same patient (in the case scenario) with clear lungs $10.1 \%$ have prescribed salbutamol or theophylline. Furthermore, one participant prescribed dexamethasone and promethazine for a patient with viral fever without vomiting.

\section{Discussion}

The first part of the study (OPD prescriptions) had only a few variables which can be studied because the patients are not available for us to crosscheck and most of the essential components like name and age are written by non-medical staff. The designation and the identification of the prescriber are notable omissions.
In the second part the overall score appears satisfactory. But it has to be noted that in a teaching hospital around $20 \%$ of doctors wrote prescriptions of poor quality.

The fact that house officers wrote better prescriptions than medical officers stresses the need for in-service training. House officers write prescriptions well because they had lectures in pharmacology regarding prescription writing within last 3 years. If the medical officers are given some training they also can perform well in prescription writing. This has been further highlighted by the fact that PGIM trainees have written the best prescriptions.

Doctors who did paediatrics for the internship wrote better paediatric prescriptions than others. If all doctors can do paediatrics for internship, paediatric prescription writing will be markedly improved. This can be achieved by doing all 4 specialties (medicine, surgery, paediatrics, obstetrics \& gynaecology) for 3 months each during the internship or extending the internship period to 2 years.

The doctors holding DCH degree prescribed better than others. DFM degree holders did not write better prescriptions than the others in our study. We think that DFM course must include prescription writing in its curriculum because it is a common examination taken by medical officers, $17.6 \%$ of medical officers in our study having this qualification..

Lastly, paracetamol, which is a common drug, is not prescribed correctly. In a teaching hospital only $46.7 \%$ have written in correct doses. $8.1 \%$ have written doses which are inappropriately high. This is a worrying fact when dengue fever is on the rise. In our study the participants were given advice regarding the correct dose of paracetamol. The doctors in other hospitals and the general practitioners must be made aware of the correct doses of paracetamol. We recommend that charts according to body weight for commonly prescribed drugs be made available in places like OPD and wards. Even though computer assisted prescription had been successful in some countries ${ }^{3}$, it is not practicable in Sri Lanka.

\section{Suggestions}

1. If all doctors are encouraged to do paediatrics for the internship, paediatric prescription writing will be improved. 
2. Regular in-service training in prescription writing is important for medical officers.

3. DFM training should give more importance to prescription writing.

4. Doses of commonly prescribed drugs must be displayed in wards and OPD.

5. Special awareness must be created regarding iatrogenic paracetamol overdose.

\section{Acknowledgements}

We thank Dr (Mrs.) M V F Jayasuriya and Dr. Mrs. Manjula Danan for helping us in the statistical analysis. We are grateful for the doctors who participated in our study despite their busy work.

\section{References}

1. Taylor B L, Selbst S M, Shah A E. Prescription writing errors in the paediatric emergency department. Paediatric Emergency Care 2005; 21(12):822-7.

2. Shaughnessy A F, Nickel R O. Prescription-writing pattern and errors in a family medicine residency program. Journal of Family Practice 1989; 29(3):290-5.

3. Bozovi K E, Beckley B E, Mc Dade M C, Adams A L, Lowe R A, Zechnich A D et al. The effect of computer-assisted prescription writing on emergency department prescription errors. Academic Emergency Medicine 2002; 9(11):116875. 